\title{
Mindfulness and academic performance: The role of compassion and engagement
}

Sandra Miralles-Armenteros ${ }^{\mathrm{a}}$, Ricardo Chiva-Gómez ${ }^{\mathrm{b} *}$, Alma Rodríguez-Sánchez ${ }^{\mathrm{b}}$ and Zina Barghouti $^{\text {b }}$

${ }^{a}$ Business and Tourism Unit, Florida Universitaria, Valencia, Spain; ${ }^{b}$ Department of Management and Marketing, Universitat Jaume I, Castellón, Spain.

Postal address:

*Corresponding author: Prof Ricardo Chiva Gómez (corresponding author). Dpto. Administración de empresas y marketing. Universitat Jaume I. Avda. Sos Baynat s/n, 12071 Castellón, Spain. Phone: +34 96438711. Email: rchiva@uji.es

\begin{abstract}
What effects does mindfulness have on university students' academic performance? Our aim in this empirical study is to analyse the relationship between mindfulness and academic performance, and how it might be explained by the role of compassion and engagement. We hypothesise that mindfulness positively relates to academic performance, and that this relationship is mediated by compassion and engagement. The study sample comprises 210 university students from management degrees, who on graduation are likely to have careers as managers or leaders in organisations. Structural equation modelling reveals that compassion partially mediates the relationship between mindfulness and engagement and, consequently, increases academic performance.
\end{abstract}

\footnotetext{
*Email: rchiva@uji.es
} 
Keywords: mindfulness; compassion; academic engagement; academic performance; undergraduates

\section{Introduction}

Academic performance is among the most important issues in academic research (Ruban \& McCoach, 2005) at both theoretical and practical levels. It is therefore essential to continue investigating its antecedents or facilitating factors.

In this line, in the last few years researchers have suggested that mindfulness can play an important role in academic performance, and have introduced it into academic research and practice. Mindfulness is a state of consciousness in which the individual is focused on the present moment, and is open to novelty, attentive to distinctions, sensitive to context and aware of multiple perspectives (Langer, 1993). Many studies have demonstrated the positive relationship between mindfulness and academic performance (Lin \& Mai, 2018; McCloskey 2015). When explaining this relationship, authors argue that mindfulness reduces stress and anxiety (McCloskey, 2015) or increases attention and memory (Lin \& Mai 2018; Sample, Thomas \& Marco, 2017), which lead to increased academic performance. However, mindfulness might also have an impact on academic performance by enhancing specific skills, such as openness, attention or inquiry, which can improve a student's ability to do well (Docksai, 2013).

Based on those skills, specifically attention, mindfulness has also been linked to other concepts like compassion (Lim, Condon \& DeSteno, 2015; Shapiro, Carlson, Astin \& 
Freedman, 2006). According to Dutton, Workman and Hardin (2014: 277), 'compassion is an interpersonal process involving the noticing, feeling, sensemaking, and acting that alleviates the suffering of another person', a definition that has been adopted by other authors in this emerging body of research (Dutton, Worline, Frost \& Lilius, 2014). Mindfulness has been linked to compassion (Lim et al., 2015; Shapiro et al., 2006) in that when someone is mindful, they are very attentive not only to other approaches or ideas but to other individuals (Shapiro et al., 2006). These authors argue that being mindful increases one's attention not only to a wider range of approaches or views when studying any subject but also to other peoples' suffering or problems. This raises the mindful individual's level of empathy, and the likelihood that they will try to help them. We therefore ask whether being compassionate through mindfulness might increase academic performance.

Furthermore, given that one of the most important antecedents of academic performance is engagement (eg. Chambel \& Curral, 2005), we ask whether it might also be positively related to mindfulness and compassion. Academic engagement is a positive and affective-cognitive state of psychological wellbeing that is characterised by vigour, dedication, and absorption (Schaufeli \& Bakker, 2004). In this sense, showing concern for others through acts of compassion has the capacity to improve one's own psychological wellbeing (Mauno, Ruokolainen, Kinnunen \& De Bloom, 2016). Additionally, and based on Fredrickson's Broaden-and-Build theory (2004), positive emotions like compassion may allow for more creative cognitive processing, and consequently for better academic performance. This theory argues that positive emotions fuel physical and psychological wellbeing, so increasing employee engagement. In sum, mindfulness increases and improves our attention on things and on the others (Van den Hurk, Giommi, Gielen, Speckens \& Barendregt, 2010), which makes us more compassionate, and then by broadening this positive emotion, we tend to be more engaged and finally to improve our academic performance. 
In line with the above arguments, we introduce two variables to explain the relationship between mindfulness and academic performance: compassion and engagement. Although both the mindfulness and academic performance literature have suggested that compassion and engagement, are important factors, to our knowledge these two variables have never been introduced to empirically test whether mindfulness is positively related to academic performance. It therefore seems reasonable to consider them in explaining this relationship. The aim of the present paper is to develop a better understanding of the causal effects of mindfulness on academic performance by introducing two mediating variables into an empirical study: compassion and engagement (Figure 1). In order to explore these relationships, we carried out a quantitative analysis of a sample of 210 final year university students from two Bachelor's degrees, one in business administration and management and the other in labour relations and human resources. These students are likely to have careers as general managers or human resource managers, and as such will take important decisions on human capital within organisations.

Insert Figure 1 about here

\section{Theoretical review}

Most literature understands that there are two main approaches to mindfulness: Eastern and Western (Weick \& Putnam, 2006; Weick \& Sutcliffe, 2006). In this paper, we will follow the Western approach (Langer, 1993; Langer \& Moldoveanu, 2000) as it has been developed more extensively in the organisational and managerial literature (Weick \& Putman, 2006). In the Eastern approach, mindfulness is equated with nonjudgmental observation, impartial 
watchfulness, nonconceptual awareness, nonegoistic alertness and awareness of change (Weick $\&$ Sutcliffe, 2006) and it is usually considered that mindfulness is attained through meditation.

In contrast, the Western approach to mindfulness involves cognitive differentiation: the process of drawing novel distinctions, reconceptualising elements within their environment in a new way, creating new categories and seeking out multiple perspectives (Langer, 1993; Langer \& Moldoveanu, 2000). Weick and Sutcliffe (2006) suggest that Western approaches to mindfulness concentrate on concepts and making distinctions, and on learning to switch modes of thinking rather than on meditation (Langer, 1993; Weick \& Sutcliffe, 2006).

Mindfulness teaches students to question their own views and beliefs and think more critically (Burke \& Hawkins, 2012). Furthermore, several papers (McCloskey, 2015; Lin \& Mai, 2018) have demonstrated that mindfulness is positively related to academic performance. We therefore propose that:

Hypothesis 1: Mindfulness is positively related to academic performance.

The study of compassion is not new: indeed scholars of religion, philosophy, sociology have been exploring this phenomenon for more than 2,000 years. However, only recently have researchers begun to investigate this concept in the field of management and academia. In fact, it was not considered worthy of study in organisations until 1999 when Peter Frost advocated the importance of compassion in the workplace. Interest has grown in this area since then, especially when Frost (2003) called for an academic response to the inevitable pain generated within organisations. The eastern approach of compassion, influenced by Buddhism, stresses the idea that in order to be compassionate we should be first aware of our craving and disturbed view of reality, feel a void (Walsh-Frank, 2008; Wong, 2006). Whereas, the western approach, that we follow in this research, mainly focuses on the external situation, on the other person's suffering (Dutton et al., 2014). 
As a relational process, compassion may be related to wellbeing and engagement by improving feelings of closeness, connectedness, trust, and social support (Crocker \& Canevello, 2008). Various psychological theories have emphasised the importance of social connections, empathy and compassion for engagement, health and wellbeing (Maslow, 1943). In this way, compassionate behaviours connect people psychologically and improve the quality of relationships among peers (Frost, Dutton, Worline \& Wilson, 2000; Powley, 2009), which improves people's wellbeing.

Mindfulness may be positively correlated to academic engagement by helping students to see activities in new and interesting ways, and shifting their perspective on what they already know (Langer \& Moldoveanu, 2000). That is, people become more interested, attentive and involved in their task, thus achieving greater participation and effort on their part in the activities they carry out (Shapiro et al., 2006). In sum, mindfulness can be positively related to engagement by encouraging attentiveness to activities and even seeing them in new ways. Mindfulness can also foster compassion, which connects people and makes them more engaged in their activities with others. These reflections lead to our second hypothesis:

\section{Hypothesis 2: The positive relationship between mindfulness and engagement is partially} mediated by compassion.

One of the main variables associated with academic performance is engagement. The close link between engagement and academic performance has already been demonstrated in the literature (El Ansari \& Stock, 2010; Pintrich \& Schrauben, 1992). Dedicated and enthusiastic students are more likely to adopt mastery approaches and achieve higher grades (Howell, 2009). Some studies have found a significant positive relationship between engagement and academic performance (Demerouti \& Bakker, 2006; Chambel and Curral, 2005). In light of the above, we propose that: 
Hypothesis 3: Academic engagement is positively related to academic performance.

\section{Research methodology}

\section{Participants and procedure}

We formed a stratified sample of 210 final year students from two four-year Bachelor's degree programmes, one in business administration and management and the other in labour relations and human resources. These students were chosen because they are likely to enter careers as general and human resource managers in the near future. The lecturer responsible for the class handed out questionnaires when the class ended and explained that the questionnaires were for a research, with no effects on students' marks, and that they were free to leave if they did not want to participate, so participation was voluntary. Furthermore, this was explained in the questionnaire itself and also that the information obtained was confidential and only to be used for the research. In the questionnaire students had to agree and sign that they accepted the researchers to link the information provided with their academic performance.

Although the lecturers did not explain the concepts analysed immediately before the questionnaire was completed, all the students had attended classes in which their lecturers had explained the meaning and importance of mindfulness, compassion and engagement in the weeks prior to the study. The mean age of the sample was 23 years $(\mathrm{SD}=3.08$; ranging from 20 to 46 years) and of these participants $58.3 \%$ were female students. Their average grade was 6.72 with a minimum of 5.69 and a maximum of 8.84 . The standard deviation was 0.60 .

\section{Measurement of the variables}


In this section, we describe the scales used to measure each of the concepts analysed.

Mindfulness was measured by seven items adapted from Langer's scale (Haigh, Moore \& Kashdan, 2011), which is a conspicuous scale of the western approach on mindfulness. One example item is: I attend to the "big picture".

Compassion was measured with the four-item compassion scale adapted by Petchsawang and Duchon (2009), which follows the Dutton et al.'s (2014) perspective, selected in this research. One example item is: "I am aware of my classmates' needs".

Engagement was measured by nine items from the scale of Engagement in academic contexts UWES-SS, devised by Schaufeli and Bakker (2003). One example item is: "When I get up in the morning I want to go to class or study".

For the three scales, respondents answered on a 7-point Likert scale ranging from 1 (strongly disagree) to 7 (strongly agree). All scales met the criterion of internal consistency (alpha) 0.70 (Nunnally \& Bernstein, 1994). The coefficient alphas were 0.790, 0.807 and 0.908, respectively, indicating the degree to which a set of items measures a single unidimensional factor construct.

Academic performance was measured by the student's final marks, which in the Spanish university system scores range from zero to ten. We obtained this data from the university records at the end of the academic year. Students' names linked the questionnaires to the university database to import the marks that the students had actually achieved in their studies.

\section{Data analysis}


First, we calculated descriptive analyses (means, standard deviations), intercorrelations and reliability analyses (Cronbach's alpha) using SPSS. Cronbach's alpha coefficient values were above 0.75 , that is, above the minimum accepted value of 0.7 (Nunnally \& Bernstein, 1994).

Given our use of subjective evaluation measures, we conducted Harman's single-factor test (Podsakoff \& Organ, 1986) to assess whether common method variance existed and to tackle potential social desirability bias in the responses.

In addition, we used structural equation modelling (SEM) methods, implemented by analysis of moment structures using AMOS software (Arbuckle, 1997), to test the research model using maximum likelihood estimation methods.

We also performed a bootstrap analysis (Preacher \& Hayes, 2004) using the Monte Carlo estimation method. This method enabled us to determine more accurately, what the direct and indirect effect of a variable was for small samples, as well as the confidence intervals of the indirect effects (Shrout \& Bolger, 2002).

\section{Results}

First, Table 1 shows the descriptive statistics, factor correlations and Cronbach's alphas of the study variables. The results of Harman's single factor test showed a poor fit: $($ Chi square $(\mathrm{df})=$ $657.048(90) ; \mathrm{p}<0.01 ; \mathrm{BBNFI}=0.429 ; \mathrm{TLI}=0.367 ; \mathrm{CFI}=0.457 ; \mathrm{RMSEA}=0.173)$. Consequently, and in accordance with this procedure, we do not consider common method variance to be a problem in our research. 
For the SEM analyses, maximum likelihood methods were used to test absolute and relative indices for goodness of fit (Marsh, Balla \& Hau, 1996). The results of the analysis of the theoretical model confirm an adequate fit of the model with the data used (Chi Square $=$ 121.533; degrees of freedom $=83 ; \mathrm{p}=0.004$; Comparative Fit Index (CFI): 0.963; BentlerBonnet Normed Fit Index $($ NFI $)=0.894$; Tucker Lewis Index $($ TLI $)=0.953$; Root Mean Square Error of Approximation $($ RMSEA $)=0.047)$. Values smaller than 0.08 for RMSEA and greater than 0.90 for the remaining indices (Hoyle, 1995) indicated an acceptable fit.

Moreover, the results from the bootstrapping analyses showed that compassion partially mediated the relationship between mindfulness and academic engagement, since the direct relationship between the latter two was significant $(\beta=.318, \mathrm{p}<0.001)$. The estimated indirect effect of mindfulness on engagement was 0.096. The 95 percent bias corrected confidence intervals for the indirect effect were between 0.017 and 0.239 , and the p-value was below 0.05 for the two-tailed significance test. Hence, the standardised indirect effect of mindfulness on academic engagement was significantly different to zero at a level of 0.001 ; we can therefore reject the null hypothesis of no mediation effect. Consequently, we can conclude that, as expected, compassion mediates the relationship between mindfulness and academic engagement.

In order to test Hypothesis 1, we must evaluate the fit of the mediating effect model. All the estimated parameters are statistically significant, with $t$ values comfortably above the minimum of 1.96. The results of the mediating model confirm an adequate fit (Chi Square/df $=$ 1.56; $\mathrm{p}=0.002 ; \mathrm{NFI}=0.903 ; \mathrm{TLI}=0.951 ; \mathrm{CFI}: 0.962 ; \mathrm{RMSEA}=0.052)$. A review of these measures leads us to conclude that the fit of this model is adequate.

Then, we estimated two structural models in order to examine whether compassion mediates in the relationship between mindfulness and engagement. The first is a direct effect 
model, which tests the effect of independent variables on dependent variables. For this mediation to exist, the coefficient in the direct effects model - referring to the effect of mindfulness on engagement - must be significant in order to continue testing the mediator effect. A second model (partial mediation) examined the same relationship with compassion acting as a mediator.

Likewise, Tippins and Sohi (2003) indicate four conditions that must be satisfied in order to confirm mediation. First, the mediation model explains more variance in engagement than the direct effect model (0.13 compared to 0.10$)$. Second, in the mediation effect model, there must be a significant relationship between mindfulness and compassion $(\beta 1=0.337 ; \mathrm{t}=$ 3.466, $\mathrm{p}<0.001)$. Third, the significant relationship between mindfulness and engagement indicated in the direct effect model $(\beta 1=0.346 ; \mathrm{t}=3.912, \mathrm{p}<0.001)$ diminishes in the mediation model $(\beta 1=0.254 ; \mathrm{t}=2.847, \mathrm{p}<0.005)$. And fourth, there is a significant relationship between compassion and engagement $(\beta 1=0.189 ; \mathrm{t}=2.056, \mathrm{p}<0.05)$. Thus, the mediation model represents a significant improvement over the direct effects model.

To test whether the mediator effect of compassion is partial or total, the mediated model must be compared to the constrained model, in which the coefficient between mindfulness and engagement is equal to zero. This shows whether the mediated model achieves a significant improvement in fit over the constrained model. If compassion causes a total mediator effect, the coefficient of the relationship between mindfulness and engagement included in the constrained model will not improve the fit. In the opposite case, the mediation would be partial.

In the direct effects model, we confirmed that the coefficient of the effect of mindfulness on engagement is significant $(\beta 1=0.318, t=3.670 \mathrm{p}<0.001)$. The fit indexes for the models are presented in Table 2. The $\mathrm{x}^{2}$ test of differences between the mediated model and the constrained model was statistically significant $(\mathrm{p}<0.01)$. The relationship between mindfulness 
and engagement in the mediated model significantly improves the fit of the constrained model, thus evidencing the partial mediation effect of compassion in the model, and confirming Hypothesis 2. Therefore, we can assume that mindfulness affects engagement both directly and indirectly (through compassion).

However, a non-significant relationship was found between mindfulness and academic performance $(\beta 1=0.069 ; \mathrm{t}=0.891, \mathrm{p}=0.373)$; hypothesis 1 is therefore not supported.

The results for the regression coefficients of the model indicate a positive relationship between engagement and academic performance $(\beta 1=0.204 ; \mathrm{t}=2.793, \mathrm{p}=0.005)$, confirming Hypothesis 3. Finally, the relationship between compassion and performance was not significant $(\beta 1=0.005 ; \mathrm{t}=0.62, \mathrm{p}=0.951)$; engagement is therefore not a mediator variable but it has a positive relationship with academic performance. That is, the greater the engagement, the better the performance will be (Figure 2).

Insert Table 1 about here

Insert Table 2 about here

Insert Figure 2 about here 


\section{Discussion}

Our goal in this study was to explore whether mindfulness relates to academic performance, and to examine the mechanisms that explain this relationship by introducing two concepts that have been suggested and tested in the mindfulness literature (compassion) and the academic performance literature (engagement). First, our findings show that mindfulness was not directly associated with performance, but that certain mechanisms could explain this relationship. In the present study, we assumed that instead of directly affecting students' academic performance, mindfulness would have an indirect effect via students' engagement. Furthermore, this relationship would be more robust when students act compassionately towards their peers. In other words, mindfulness facilitates students' compassion and this will lead to increased levels of engagement and, consequently, of academic performance.

Although some studies have shown a positive and significant relationship between mindfulness and academic performance (Lin \& Mai, 2018; McCloskey, 2015), the present study revealed no significant direct relationship. The discrepancy of results may be because in those studies, students had previously attended a mindfulness training programme (e.g., mindfulnessbased stress reduction programmes, meditation practices), which may have caused the results to be significantly positive. In our case, the lecturers explained the concepts of mindfulness, compassion and engagement, but the effect of these theoretical classes was probably unlike that of other practical training programmes. Indeed, training programmes have demonstrated significant effects in enhancing participants' general levels of mindfulness (Carlson \& Brown, 2005), which has implications for participants' academic performance. 
Once the notable benefits of mindfulness are known, and given the empirical evidence that mindfulness can be increased via various interventions (Smith et al., 2008), it would be interesting to promote programmes that foster the level of mindfulness among university students. Indeed, many universities have initiated mindfulness practices as a way of decreasing exam anxiety, and improving students' attention and the environment both inside and outside the classroom (Docksai, 2013). Furthermore, essential prosocial behaviours, such as compassion, should be promoted in universities. Encouraging certain habits and positive behaviours (i.e., mindfulness and compassion) during their time at university could improve the behaviour of these students in their future careers. It is important to stress that the students of business administration and labour relations and human resources are tomorrow's company managers, people who will be dealing with problems and managing human capital and talent. Furthermore, research underlines the idea that mindfulness and compassion are essential for leadership effectiveness (eg. Reave, 2005; Wasylkiw, Holton, Azar \& Cook, 2015). It therefore seems essential for educators to train them in such matters, not only theoretically but also through practical programmes. In this way, students would learn and experience that being mindful and compassionate make individuals more engaged and enhance their academic performance.

The study has a number of limitations that should be acknowledged. First, the sample size was small and self-selected, and therefore the results may not be generalisable to university students as a whole, since our sample of students were from the final year of only two specific degree courses. An additional limitation is the cross-sectional nature of our study, which does not allow us to draw any conclusions about the direction of causality in the associations observed. Relationships among these variables should be followed up with longitudinal studies to investigate them more precisely. This would reveal the impact of one variable on another, which is important when considering mediation (MacKinnon, 2008). In fact, future longitudinal 
research could explore the dynamic reciprocal nature of all the study variables. Another limitation of the research is the selection of scales to assess the variables: they are very specific of the approaches followed in this research. Future research might try different perspectives and scales.

This article addresses unanswered questions about the effect of mindfulness on academic performance and the mechanism that can influence this relationship. Specifically, the study makes a key contribution, namely that academic performance can be improved by promoting students' engagement. In this sense, mindfulness and compassion seem to be powerful enhancers of engagement, and as such they should be promoted in universities in order to prepare students to face the working world with all the tools that society demands of them. Thus, not only will we achieve a situation in which universities are places where values and engagement are constructed, but also a more humane society as a whole.

\section{Acknowledgements}

This work was supported by the Universitat Jaume I under Grants P1·1B2013-14 and UJIA2017-05.

\section{Notes on contributors}

Sandra Miralles-Armenteros has a PhD in Economics and Business from Universitat Jaume I. Her main research interest is organizational and people development. She has participated in 
numerous scientific congresses both on management and organizational behavior topics. Furthermore, she has made an international research stay at the University of Helsinki collaborating with a pioneering research group in her main topic of interest: compassion at work. She is currently Associate Professor in Florida Universitaria in Valencia.

Ricardo Chiva-Gómez is Full Professor of Management and Organizations at Universitat Jaume I in Castellón, Spain. He has been visiting professor at King's College London and University of Liverpool. He has published his research at journals such as International Journal of Management Reviews, Management Learning, or Journal of Product Innovation Management. His current research interests are Organizational Learning. Human Resource Management and Development drawing on interdisciplinary theories and methods.

Alma M. Rodríguez-Sánchez is Associate Professor of Management and Organizations at Universitat Jaume I in Castellon, Spain. She has been visiting scholar at Utrecht University (The Netherlands); Finnish Institute of Occupational Health (Finland) and Helsinki University (Finland). Her research is focused on wellbeing at work, compassion, flow, engagement, creativity and resilience. She has published in international journals such as Work \& Stress; Group \& Organization Management; European Journal of Work and Organizational Psychology; Stress \& Health; Journal of Occupational and Organizational Psychology among others. 
Zina Barghouti is University Master student at Universitat Jaume I in Castellon, Spain. She has degree in Business Administration at Universitat Jaume I. Her research interest are organizational trust, organizational change and human development within organizations.

\section{References}

Arbuckle, J. L. (1997). Amos user's guide: Version 3.6, Chicago: SmallWaters Corp.

Burke, A., \& Hawkins, K. (2012). Mindfulness in education. Encounter, 25, 36-40.

Carlson L. E., Brown K.W. (2005) Validation of the Mindful Attention Awareness Scale in a cancer population. Journal of Psychosomatic Research, 58 (1), 29-33.

Chambel, M. J., \& Curral, L. (2005). Stress in academic life: Characteristics as predictors of student well-being and performance. Applied Psychology: An International Review, 54, 135-147.

Crocker, J., \& Canevello, A. (2008). Creating and undermining social support in communal relationships: The role of compassionate and self-image goals. Journal of Personality and Social Psychology, 95, 555-575.

Demerouti, E., \& Bakker, A. B. (2006). Employee well-being and job performance: Where we stand and where we should go. In S. Mcintyre \& J. Houdmont (Eds.), Occupational health psychology: European perspectives on research, education and practice (Vol. 1, pp. 83-111). Maia, Portugal: ISMAI Publications.

Docksai, R. (2013). A mindful approach to learning. The Futurist, 47, 8-10.

Dutton, J. E., Workman, K. M., \& Hardin, A. E. (2014). Compassion at work. Annual Review of organizational Psychology and Organizational Behavior, 1, 277-304.

Dutton, J. E., Worline, M.C., Frost, P. J., \& Lilius, J. M. (2006). Explaining compassion organizing. Administrative Science Quarterly, 51, 59-96. 
El Ansari W., \& Stock C. (2010). Is the health and wellbeing of university students associated with their academic performance? Cross sectional findings from the United Kingdom. International Journal of Environmental Research and Public Health, 7, 509-527.

Fredrickson, B. L. (2004) The broaden-and-build theory of positive emotions. Philosophical Transactions of the Royal Society B: Biological Sciences, 359, 1367-1377.

Frost, P. J. (2003). Toxic emotions at work: How compassionate managers handle pain and conflict. Boston, MA: Harvard Business School Press.

Frost, P. J., Dutton, J. E., Worline, M. C., \& Wilson, A. (2000). Narratives of compassion in organizations. In S. Fineman (Ed.). Emotion in organizations (2nd Ed.), (pp. 25-45). London: Sage.

Haigh, E. A. P., Moore, M. T., Kashdan, T. B., \& Fresco, D. M. (2011). Examination of the factor structure and concurrent validity of the langer mindfulness/mindlessness scale. Assessment, 18, 11-26.

Howell, A. J. (2009). Flourishing: Achievement-related correlates of students' well-being. Journal of Positive Psychology, 4, 1-13.

Langer, E. J. (1993). A mindful education. Educational Psychologist, 28,43-50.

Langer, E. J., \& Moldoveanu, M. (2000). Mindfulness research and the future. Journal of Social Issues, 56, 129-139.

Lim, D., Condon, P., \& DeSteno, D. (2015). Mindfulness and compassion: An examination of mechanism and scalability. PLoS ONE, 10, e0118221.

Lin, J. W., \& Mai, L. J. (2018). Impact of mindfulness meditation intervention on academic performance. Innovations in Education and Teaching International, 55, 366-375.

Marsh, H. W., Balla, J. R., \& Hau, K. T. (1996). An evaluation of incremental fit indices: A clarification of mathematical and empirical processes. In G. A. Marcoulides \& R. E. 
Schumacker (Eds.), Advanced structural equation modeling techniques (pp. 315-353). Mahwah, NJ: Lawrence Erlbaum.

Maslow, A. H. (1943). A theory of human motivation. Psychological Review, 50, 370-396.

Mauno, S., Ruokolainen, M., Kinnunen, U., \& De Bloom, J. (2016). Emotional labour and work engagement among nurses: Examining perceived compassion, leadership and work ethic as stress buffers. Journal of Advanced Nursing, 75, 1169-1181.

McCloskey, L. E. (2015). Mindfulness as an intervention for improving academic success among students with executive functioning disorders. Procedia - Social and Behavioral Sciences, 174, $221-226$

Nunnally, J. C., \& Bernstein, I. H. (1994). Psychometric theory (3rd Ed.). New York: McgrawHill.

Petchsawanga, P., \& Duchon, D. (2009). Measuring workplace spirituality in an Asian context. Management Department Faculty Publications. Paper 93.

Pintrich, P. R., \& Schrauben, B. (1992). Students' motivational beliefs and their cognitive engagement in classroom academic tasks. In D. Schunk \& J. Meece (Eds.), Student perceptions in the classroom. (pp. 149-183). Hillsdale, NJ: Lawrence Erlbaum Associates.

Podsakoff, P. M., \& Organ, D. W. (1986). Self-reports in organizational research: Problems and prospects. Journal of Management, 12, 69-82.

Powley E. H. (2009). Reclaiming resilience and safety: Resilience activation in the critical period of crisis. Human Relations, 62, 1289-1326.

Preacher, K. J., \& Hayes, A. F. (2004). SPSS and SAS procedures for estimating indirect effects in simple mediation models. Behavior research methods, instruments, \& computers, 36 , 717-731. 
Reave, L. (2005). Spiritual values and practices related to leadership effectiveness. The Leadership Quarterly, 16, 655-687.

Ruban, L. M., \& Mccoach, D. B. (2005). Gender differences in explaining grades using structural equation modeling. Review of Higher Education, 28, 475-502.

Sample J., Thomas M., \& Marco R. F. (2017) A randomized controlled pilot intervention study of a Mindfulness-Based Self-Leadership Training (MBSLT) on stress and performance. Mindfulness, 8, 1393-1407. Published online 2017 Apr 28.

Schaufeli, W. B., \& Bakker, A. B. (2003). Utrecht work engagement scale: Preliminary manual. Department of Psychology, Utrecht University: The Netherlands.

Shapiro, S., Carlson, L., Astin, J., \& Freedman, B. (2006). Mechanisms of mindfulness. Journal of Clinical Psychology, 62, 373-386.

Shrout, P. E., \& Bolger, N. (2002). Mediation in experimental and nonexperimental studies: new procedures and recommendations. Psychological methods, 7, 422.

Smith, B., Shelley, B., Dalen, J., Wiggins, K., Tooley, E., \& Bernard, J. (2008). A pilot study comparing the effects of mindfulness-based and cognitive-behavioral stress reduction. Journal of Alternative and Complementary Medicine, 14, 251-258.

Tippins, M. J., \& Sohi, R. S. (2003). Information Technology competency and firm performance: Is organizational learning a missing link? Strategic Management Journal, $4,745$.

Van den Hurk, P. A., Giommi, F., Gielen, S. C., Speckens, A. E., \& Barendregt, H. P. (2010). Greater efficiency in attentional processing related to mindfulness meditation. The Quarterly Journal of Experimental Psychology, 63, 1168-1180.761.

WalshपFrank, P. (2008) Compassion: An east $\square$ west comparison. Asian Philosophy An International Journal of the Philosophical Traditions of the East, 6, 5-16. 
Wasylkiw, L., Holton, J., Azar R., \& Cook W. (2015) The impact of mindfulness on leadership effectiveness in a health care setting: a pilot study. Journal of Health Organization and Management, 9, 893-911.

Weick, K. E., \& Putnam T. (2006). Organizing for mindfulness: Eastern wisdom and Western knowledge. Journal of Management Inquiry, 15, 275-87

Weick, K., \& Sutcliffe K. M. (2006). Mindfulness and the quality of organizational attention. Organization Science, 17, 514-524.

Wong, P. T. P. (2006). The nature and practice of compassion: Integrating western and eastern positivce psychologies. PsycCRITIQUES, 51, art 16. 


\section{FIGURES}

Figure 1. Conceptual Model of the Research

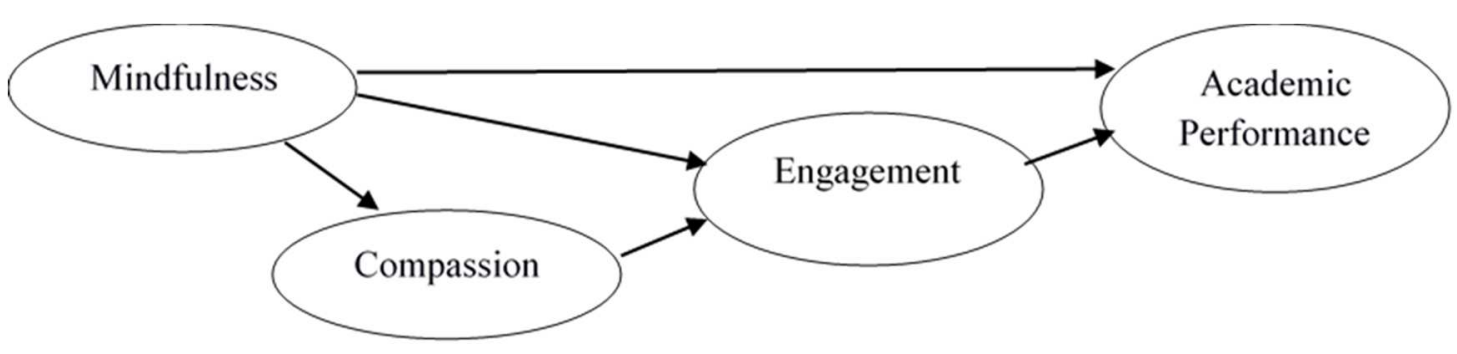

Figure 2. Results of the Theoretical Model.

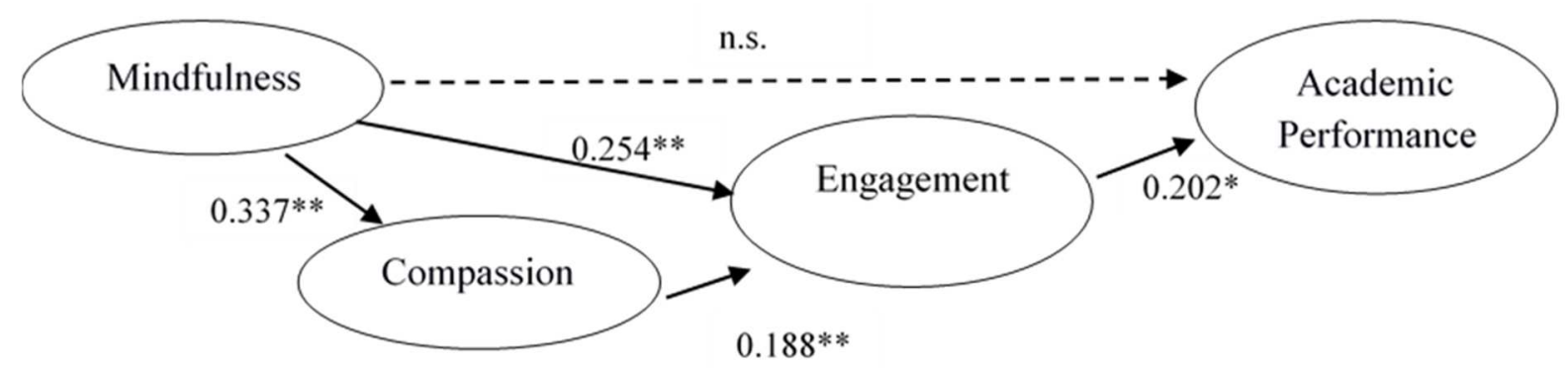

Note: $* *<0.01 ; *<0.05$ 


\section{TABLES}

Table 1. Factor correlations, means, standard deviations, and Cronbach's Alphas

\begin{tabular}{|c|c|c|c|c|c|c|}
\hline Variables & Mean & SD & 1 & 2 & 3 & 4 \\
\hline 1. Mindfulness & 5.215 & .804 & $(0.790)$ & & & \\
\hline 2. Compassion & 5.466 & .903 & $.275^{* *}$ & $(0.807)$ & & \\
\hline 3. Engagement & 4.724 & 1.012 & $.248 * *$ & $.260 * *$ & $(0.908)$ & \\
\hline 4.Academic performance & 6.721 & .604 & .075 & .011 & $.192 * *$ & 1 \\
\hline \multicolumn{7}{|c|}{ Note: $* *<0.01$ (two-tailed); $\mathrm{n}=210$} \\
\hline
\end{tabular}

Table 2. Fit indices for the structural models

\begin{tabular}{lccccccc}
\hline Variables & Chi square & df & p & NFI & TLI & CFI & RMSEA \\
\hline Direct effect model & 42.881 & 32 & 0.095 & 0.094 & 0.984 & 0.991 & 0.045 \\
Mediated model & 109.384 & 70 & 0.002 & 0.903 & 0.951 & 0.962 & 0.052 \\
Constrained model & 117.845 & 71 & 0.000 & 0.896 & 0.942 & 0.955 & 0.056 \\
\hline
\end{tabular}

